\title{
Secondary ice production during the break-up of freezing water drops on impact with ice particles
}

\author{
Rachel L. James ${ }^{1}$, Vaughan T. J. Phillips ${ }^{2}$, and Paul J. Connolly ${ }^{1}$ \\ ${ }^{1}$ Department of Earth and Environmental Science, The University of Manchester, Manchester, UK \\ ${ }^{2}$ University of Lund, Lund, Sweden
}

Correspondence: Rachel L. James (rachel.james@manchester.ac.uk)

\begin{abstract}
We experimentally investigated collisions of supercooled water drops ( $\sim 5 \mathrm{~mm}$ in diameter) with ice particles of a similar size placed on a glass slide at temperatures $\mathrm{T} \geq-12{ }^{\circ} \mathrm{C}$. Our results showed that secondary drops were generated during both the spreading and retraction phase of the supercooled water drop impact. The secondary drops generated during the spreading phase were emitted too fast to quantify. However, quantification of the secondary drops generated during the retraction phase with diameters $>0.1 \mathrm{~mm}$ showed that 5-10 secondary drops formed per collision, with approximately $30 \%$ of the secondary drops freezing over a temperature range of $-4{ }^{\circ} \mathrm{C} \leq \mathrm{T} \leq-12{ }^{\circ} \mathrm{C}$. Our investigation provides the first dedicated laboratory study of collisions of supercooled water drops with ice particles as a secondary ice production mechanism. Our results suggest that this secondary ice production mechanism may be significant for ice formation in atmospheric clouds containing large supercooled drops and ice particles.
\end{abstract}

\section{Introduction}

Most surface rainfall events that occur across the globe are associated with the ice-phase within clouds in the Earth's atmosphere (Field and Heymsfield, 2015), as are severe weather events such as freezing rain, hail and thunderstorms (Changnon, 2003; Púčik et al., 2019; Elsom, 2001). Therefore, understanding the processes which govern ice formation in clouds is crucial for determining their effects on both climate and weather.

Where temperatures are warmer than the homogeneous freezing point, $\mathrm{T}>-35{ }^{\circ} \mathrm{C}$, supercooled water drops can heterogeneously freeze via solid aerosol particles present in the atmosphere. These solid aerosol particles, called ice nucleating particles (INPs), are relatively rare, and while number concentrations of INPs vary in time and space, they are typically less than $1 \times 10^{-5} \mathrm{~L}^{-1}$ to $1 \mathrm{~L}^{-1}$ at temperatures $T \sim-10^{\circ} \mathrm{C}$ (Kanji et al., 2017). Yet, observed ice particle concentrations in mixedphase clouds can be several orders of magnitude higher than concentrations predicted from ice particles forming due to INPs (e.g. Crawford et al., 2012; Lloyd et al., 2015; Lasher-Trapp et al., 2016; Ladino et al., 2017). Ice can also form at $\mathrm{T}>-35^{\circ} \mathrm{C}$ via secondary ice production (SIP) where new ice particles are formed from pre-existing ice particles. However, our understanding of ice formation from SIP mechanisms is incomplete (e.g. see reviews by Field et al., 2017; Korolev and Leisner, 2020), resulting in poor representation of SIP mechanisms in numerical weather prediction (NWP) models. As such, NWP 
models underestimate the concentrations of ice particles in mixed-phase clouds, severely for cumuliform clouds (Crawford et al., 2012).

Several SIP mechanisms have been identified and studied both in the laboratory and theoretically, but only the rimesplintering SIP mechanism is widely implemented in NWP models. Active between $-3{ }^{\circ} \mathrm{C} \leq \mathrm{T} \leq-8{ }^{\circ} \mathrm{C}$, rime-splintering occurs when supercooled water drop diameters are $<13 \mu \mathrm{m}$ or $>24 \mu \mathrm{m}$ (Hallett and Mossop, 1974; Mossop and Hallett, 1974; Mossop, 1978). Another SIP mechanism, the fragmentation of freezing drops, has received a significant proportion of laboratory based SIP investigations. Fragmentation due to freezing drizzle or raindrops can occur over a wider temperature range between $0{ }^{\circ} \mathrm{C}<\mathrm{T}<-32{ }^{\circ} \mathrm{C}$ than rime-splintering, but quantification between laboratory studies varies significantly (see Table 1 of Korolev and Leisner, 2020, for a summary). While other SIP mechanisms exist (e.g. ice-ice collisions, sublimation fragmentation), the attention, especially of laboratory studies, has overwhelmingly focussed on the rime-splintering and fragmentation due to freezing drops SIP mechanisms. Furthermore, unidentified SIP mechanisms may also exist.

In this paper, we present a SIP mechanism involving the formation of secondary drops from the collision of a supercooled water drop with an ice particle. This SIP mechanism has been investigated via a theoretical study by Phillips et al. (2018), but not directly via laboratory studies, although indirect laboratory studies of aspects of this process do exist. For example, a similar mechanism was alluded to by Latham and Warwicker (1980) in their experimental investigation of charge transfer during interactions between hailstones and supercooled drops. They observed that frost could occasionally be broken during impact, thus forming new ice particles. Although this was an unwanted outcome of their experiments it provided some hints of a potential SIP mechanism during the interactions between ice particles and supercooled raindrops. Later, Schremb et al. (2018) studied the fluid flow and solidification of supercooled water drops on elevated ice targets, briefly observing the formation of secondary drops from the rim of the supercooled water drop during impact. However, for both of these studies no quantification of the secondary drops was made.

In this paper, we describe a set of experiments performed at the University of Manchester to determine the freezing fraction of secondary drops, $\Phi$, formed during the collision of a mm sized supercooled raindrop on an ice particle, providing the first laboratory quantification of this SIP mechanism. The theory of collisions of a supercooled water drops with an ice particle from Phillips et al. (2018) is given in Section 2. The experimental setup is described in Section 3. The results are presented in Section 4, and the discussion in Section 5. Finally, the conclusions are given in Section 6.

\section{Theory}

The theoretical study by Phillips et al. (2018) considered the fragmentation of freezing water drops during collisions of supercooled water drops with ice particles more massive, referred to as 'Mode 2'. When collided with more massive ice particles, the spherical symmetry of a supercooled water drop is not maintained, with the potential to fragment at impact, emitting secondary drops. Due to a lack of laboratory investigations on this SIP mechanism, Phillips et al. (2018) used dimensionless energy (DE) as described by Testik et al. (2011) to determine if fragmentation occurred based on the ratio between the kinetic energy $\left(K_{0}\right)$ 
at impact and surface energy:

$K_{0}=\frac{1}{2}\left(\frac{m \times m_{i}}{m+m_{i}}\right)\left(v-v_{i}\right)^{2}$

$D E=\frac{K_{0}}{\gamma_{l i q} \pi D^{2}}$

where $m$ is the mass of the supercooled drop, $m_{i}$ is the mass of the ice particle, $v$ is the velocity of the supercooled water drop, $v_{i}$ is the velocity of the ice particle, $\gamma_{l i q}$ is the surface tension of liquid water and $\mathrm{D}$ is the diameter of the drop.

A power law was fitted to the experimental data of Levin et al. (1971) for a $2.5 \mathrm{~mm}$ water drop impacting a rough copper hemisphere at room temperature to estimate the number of secondary drops formed, $N_{s}=3 \times \max \left(D E-D E_{c r i t}, 0\right)$ where $D_{\text {crit }} \sim 0.2$. After accounting for the fractional depletion of liquid water at the end of stage 1 of freezing, the number of secondary drops $\left(N_{s}\right)$ formed in the collision of a supercooled water drop with an ice particle more massive was determined. This yielded the number of secondary ice particles per collision $\left(N_{i}\right)$ :

$N_{i}=N_{s} \times \Phi=3 \Phi \times[1-f(T)] \times \max \left(D E-D E_{c r i t}, 0\right)$

where $\mathrm{f}$ is the initial fraction by mass of a drop frozen at stage 1 of freezing $f(T)=-c_{w} T / L_{f}$ given that $c_{w}$ is the specific heat capacity of water, $\mathrm{T}$ is the initial freezing temperature $\left({ }^{\circ} \mathrm{C}\right)$ and $L_{f}$ is the specific latent heat of freezing; and $D E_{c r i t}$ is equal to $\sim 0.2$. Finally, Phillips et al. (2018) hypothesised that $\Phi(T)=\min [4 f(T), 1]$ such that $\Phi=0.5$ at $-10{ }^{\circ} \mathrm{C}$.

Despite these theoretical hypotheses and approximations, implementation of 'Mode 2' in a parcel model with bin microphysics gave adequate agreement with Ice Cloud Experiment-Tropical (ICE-T) observational data (Lawson et al., 2015).

\section{Experimental Setup}

A schematic of the experimental setup is shown in Fig. 1. The setup was purpose-built to study the impact of a supercooled water drop on an ice particle. For this study, we used two configurations of the experimental setup. The first configuration was used to study the drop impact with a high-speed camera (Chronos 1.4, Kron Technologies Inc.) equipped with a microscopic lens (Kron Technologies Inc.) and a $0.5 \times$ barlow lens (Kron Technologies Inc.) in a side-on view. The second configuration was used to quantify the fraction of secondary drops that froze after impact with the ice particle using two Raspberry Picameras (Raspberry PiCamera Module V2) referred to as RPicams, with a polarising filter (Standard $55 \mathrm{~mm}$ Circular Polariser) attached to one camera. At present, the two configurations are not compatible to work concurrently. Recordings using the high-speed camera were recorded at 1069 frames per second and recordings using the RPicameras were recorded at 24 frames per second.

The experimental setup is operated in a cold room which can achieve a base temperature as low as $-50{ }^{\circ} \mathrm{C}$ and provided the means of achieving a supercooled environment. The experimental setup was housed in a Bosch strut/Perspex panel frame to prevent the accidental introduction of frost particles during the experiments. A glass slide was supported on 3D printed plastic 
stilts approximately $10 \mathrm{~cm}$ in height which had a fan attached to dissipate the heat emitted from the polarised light source (LCD monitor). The temperature of the glass slide was monitored using a K-type thermocouple attached to the glass slide with aluminium tape. The relative humidity was not measured, but will be below ice saturation. The ice particles were prefabricated by freezing ultrapure water drops (Endotoxin-Free UP H2O, Merck) of approximately $6 \mathrm{~mm}$ in diameter on a glass slide coated in a water repellent (Rain-X) using a Peltier cooling system. The typical freezing shape of the ice particle is shown in Fig. 1. A pipette was modified to allow an ultrapure water drop (Endotoxin-Free UP H2O, Merck) at room temperature with a diameter of approximately $5 \mathrm{~mm}$ to be placed on the pipette using a disposable needle (22 gauge, sterile) and syringe. The modified pipette was held in a 3D printed tipper mechanism parallel to the glass slide, and the water drop was allowed to reach thermal equilibrium with the cold room for $90 \mathrm{~s}$. The supercooled drop was released from the modified pipette perpendicular to the glass slide and was controlled by an Arduino and servo motor. The tipper was attached to an $x-y$ translator (modified 3D printer) to allow multiple drop impact experiments using the same glass slide.

As the drop height and supercooled water drop diameter $(D)$ were kept constant at $1.36 \mathrm{~m}$ and $5 \mathrm{~mm}$, respectively, the impact velocity $\left(\mathrm{V}_{0}\right)$ for all experiments was $5.2 \mathrm{~m} \mathrm{~s}^{-1}$. The supercooled water drop and the ice particle/glass slide were in thermal equilibrium for all experiments. The temperature range investigated was between $-4{ }^{\circ} \mathrm{C}$ to $-12{ }^{\circ} \mathrm{C}$. As the temperature of water decreases, the surface tension $(\sigma)$ and viscosity $(\lambda)$ of water increases (Hrubý et al., 2014; Dehaoui et al., 2015). In fluid dynamics, the Weber number, We $=\rho D V_{0}^{2} / \sigma$, and Reynolds number, $\operatorname{Re}=\rho D V_{0} / \mu$, are used to relate inertial forces to interfacial and viscous forces, respectively. Taking into account the temperature dependent values of surface tension and viscosity of the supercooled water between $-4{ }^{\circ} \mathrm{C} \leq \mathrm{T} \leq-12{ }^{\circ} \mathrm{C}$, the We and Re number ranges obtained were $1747 \leq \mathrm{We} \leq 1772$ and $8781 \leq \operatorname{Re} \leq 12240$, respectively.

\section{Results}

\subsection{Drop impact: high-speed recordings}

We performed control experiments at room temperature $\left(23^{\circ} \mathrm{C}\right)$ and several supercooled temperatures using the high-speed camera configuration to characterise the water drop (diameter of $5 \mathrm{~mm}$ ) impact of the glass slide. Figure 2 shows the frames from a high-speed recording of (a) a water drop impact on the glass slide at room temperature and (b) a supercooled water drop impact at $-5{ }^{\circ} \mathrm{C}$.

On impact with the glass slide, the water drop deformed and spread radially outwards as a thin film bordered by a thicker rim. Instabilities at the rim were observed for both the room temperature drop and the supercooled drop at $-5{ }^{\circ} \mathrm{C}$. The supercooled drop shown in Fig. 2(b) ejected straight filament-like structures at an angle to the glass surface close to the impact and these filament-like structures disintegrated into secondary drops. This was in contrast to the impact of the water drop at room temperature drop where no ejection of filament-like structures was observed. During the retraction phase, some of the rim instabilities pinched off from the thin film in the experiments with water drop at room temperature forming secondary drops, in a process called 'receding break-up'. In contrast, no receding break-up was observed for the supercooled drop. 


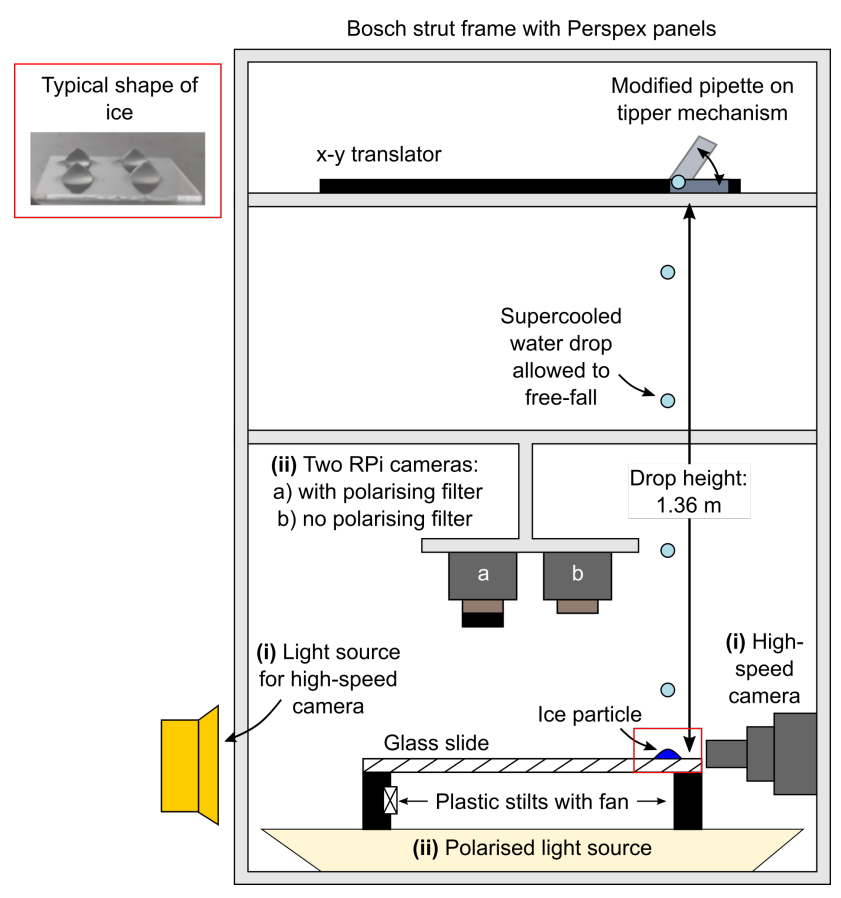

Figure 1. Schematic diagram of the experimental setup. Components labeled (i) were used in the high-speed configuration and (ii) were used in the RPicams configuration. The setup was operated in a cold room to achieve a supercooled environment.

Figure 3 shows the frames of a supercooled water drop impacting the side of an ice particle at $-5^{\circ} \mathrm{C}$. Similar to the supercooled water drop on a glass slide, filament-like structures which dissipated into secondary drops formed at or close to impact with the glass slide/ice particle. Unlike the impact of a supercooled water drop on a bare glass slide, secondary drops formed via receding break-up. These secondary drops were observed around the parts of the rim of the thin film which contacted the ice particle.

\subsection{Determining the freezing fraction of the secondary drops: RPicams}

We performed supercooled water drop impacts on ice particles over a temperature range from $-4{ }^{\circ} \mathrm{C} \leq \mathrm{T} \leq-12{ }^{\circ} \mathrm{C}$. To unambiguously identify if a secondary drop had frozen, we used a polarising filter with a polarised light source, exploiting the birefringent properties of ice. Figure 4 shows selected frames of a supercooled water drop impact at $-4{ }^{\circ} \mathrm{C}$ using the RPicams configuration. The top row of Fig. 4 shows frames from the camera with no polarising filter (a) before, (b) at and (c) $\sim 10 \mathrm{~s}$ after impact. The number of secondary drops observed are indicated by red arrows in Fig. 4 (c). The difference between the Fig. 4 (a) and (c) is presented in Fig. 4 (d) clearly indicating the secondary drops formed. The bottom row shows frames from the camera with a polarising filter (e) before, (f) at and (g) $\sim 10 \mathrm{~s}$ after impact. The frozen secondary drop is indicated by a white arrow in Fig. 4 (g). The difference between the Fig. 4 (e) and (g) is presented in Fig. 4 (h) clearly indicating the frozen secondary drop formed. For this particular experiment, five secondary drops formed, of which one froze, giving a freezing fraction, $\Phi=$ 


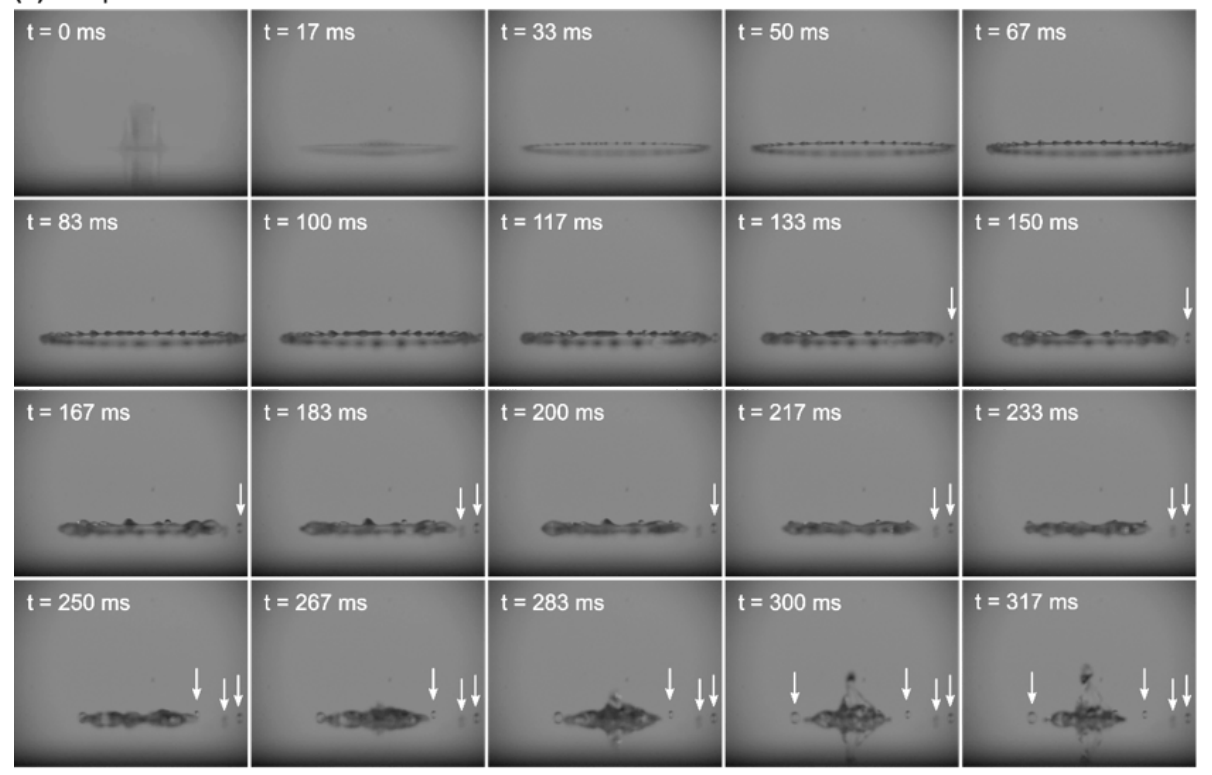

(b) Temperature: $-5^{\circ} \mathrm{C}$

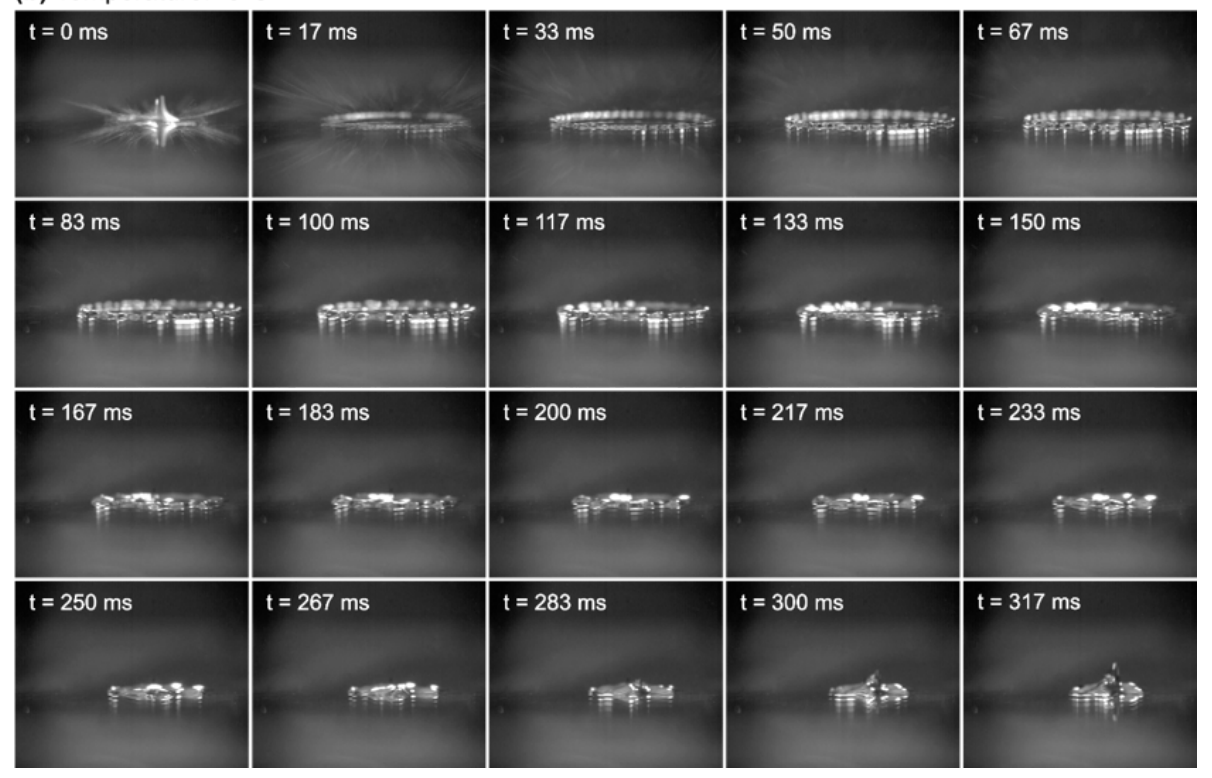

Figure 2. Frames from the high-speed camera configuration of a water drop impact on a glass slide when both water drop and glass slide are at (a) room temperature $\left(23^{\circ} \mathrm{C}\right)$ and $(\mathrm{b})-5^{\circ} \mathrm{C}$. Arrows indicate secondary drop formation during retraction phase of the water drop. 


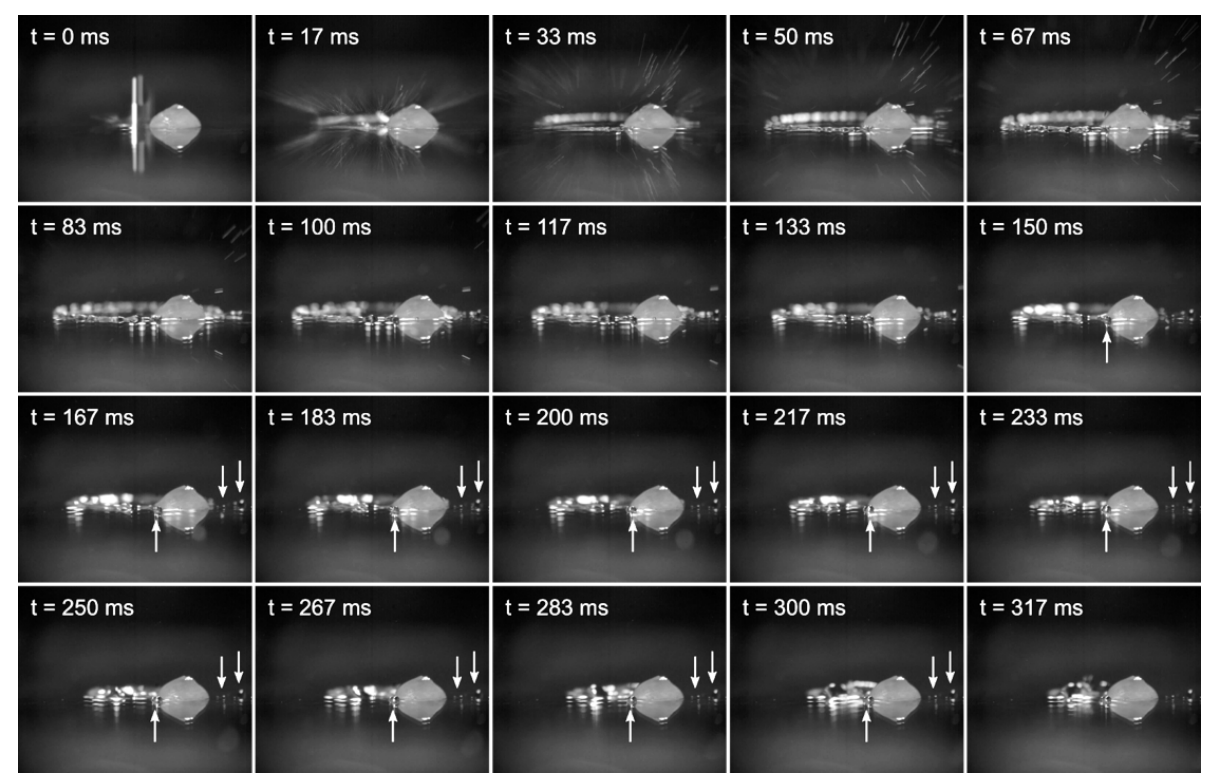

Figure 3. Frames from the high-speed camera setup of a supercooled water drop impact on an ice particle when both drop and ice particle are at $-5^{\circ} \mathrm{C}$. Arrows indicate secondary drop formation during the retraction phase of the supercooled water drop.
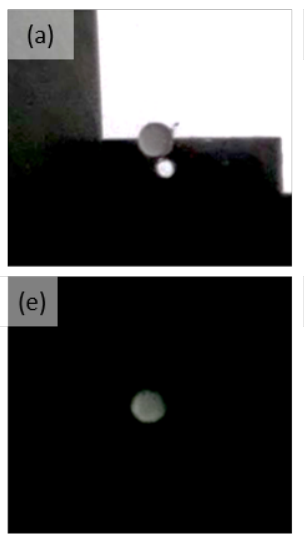
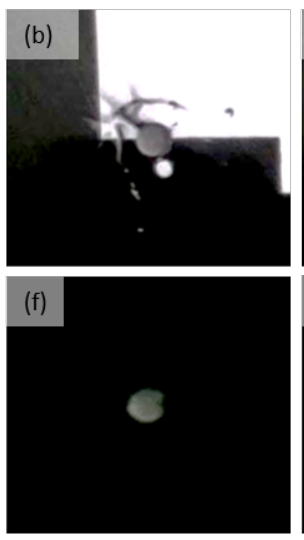
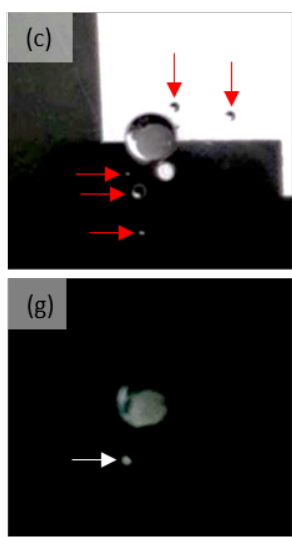

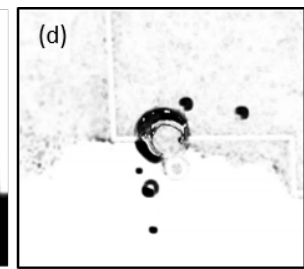

(h)

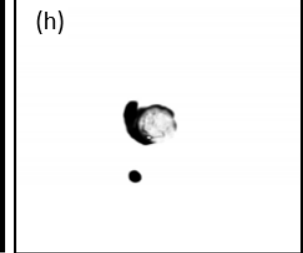

Figure 4. Selected frames from the impact of a supercooled water drop on an ice particle at $-4^{\circ} \mathrm{C}$ using the RPicams configuration. Frames (a)-(c) before, at and $\sim 10 \mathrm{~s}$ after impact using the camera with no polarising filter. Red arrows in (c) indicate the number of secondary drops formed. Frame (d) shows the difference between (a) and (c). Frames (e)-(g) before, at and $\sim 10 \mathrm{~s}$ after impact using the camera with a polarising filter. The white arrow in (h) indicates the frozen secondary drop. Frame (h) shows the difference between (e) and (g).

0.2. During these experiments, two types of supercooled water impacts occurred: direct impact on the ice particle and partial impact on the ice particle. These different impacts arose due to practical difficulties with consistently impacting the ice particle with supercooled water drop due to changes in viscosity of water at different temperatures. For the experiment shown in Fig. 4, the impact was a side impact towards the top left of the ice particle as indicated in Fig. 4 (b). The RPicams configuration 


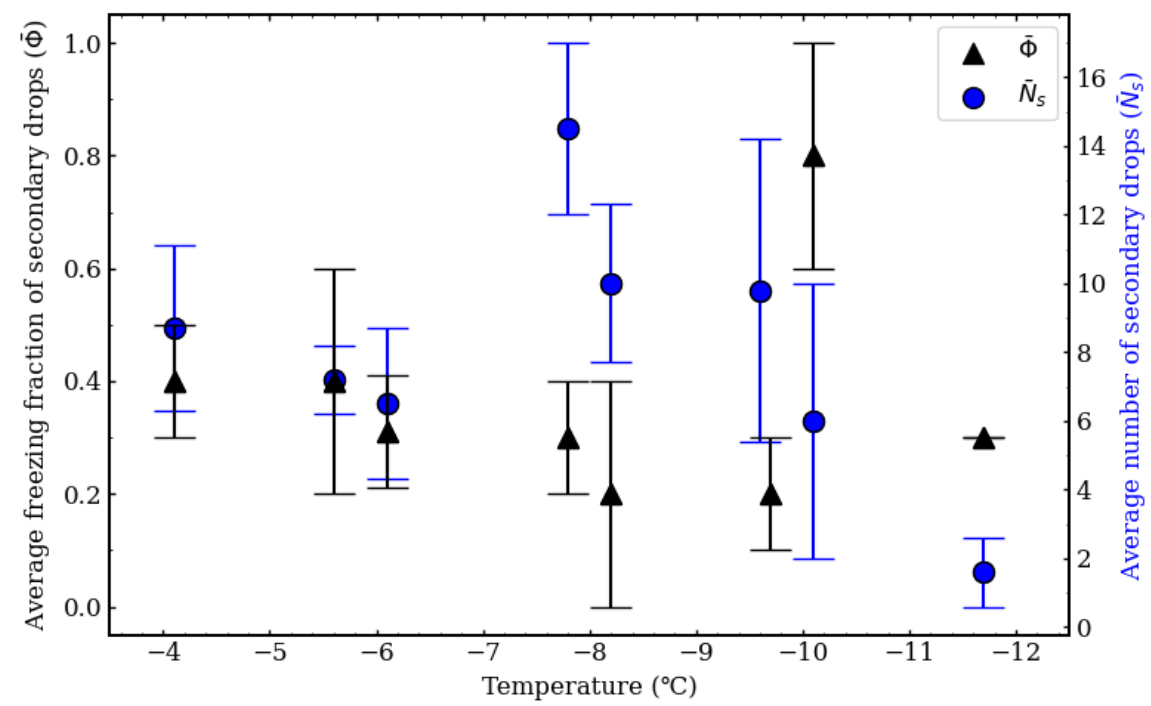

Figure 5. The freezing fraction of the secondary drops $(\bar{\Phi})$ (left y-axis, black triangles) and the average number of secondary drops (right $\mathrm{y}$-axis, blue circles) as a function of temperature.

only observed the larger $>0.1 \mathrm{~mm}$ diameter drops formed during retraction of the thin film. The smaller secondary drops $(<0.1 \mathrm{~mm})$ observed at impact from the high-speed configuration were not observed using this configuration as the minimum drop diameter the RPicams could detect was $0.1 \mathrm{~mm}$.

Figure 5 shows the average freezing fraction of secondary drops formed when a supercooled water drop with a diameter of $5 \mathrm{~mm}$ collided with an ice particle, $\bar{\Phi}$, plotted on the left y-axis as a function of temperature. The raw data can be found in Table A1 and the averaged data of the freezing fraction of secondary drops in Table A2. The average number of secondary drops, $\bar{N}_{s}$, liquid or solid, is plotted on the right y-axis of Fig. 5 as a function of temperature, which reached a maximum at approximately $-7.5^{\circ} \mathrm{C}$. The averaged data of the number of secondary drops can be found in Table A3.

\section{Discussion}

145 From our high-speed and RPicams recordings we present a schematic diagram of the formation of secondary drops from a supercooled water drop impact on an ice particle in Fig. 6. The We and Re numbers used were sufficiently large, i.e. We » 2.5 and $R e » 25$, such that inertia dominated the spreading of the thin film (Roisman, 2009). Surface tension and viscosity forces were considered negligible during the spreading phase of the drop (Roisman, 2009), as was the wettability of the surface (Antonini et al., 2012). Figure 6(a) depicts the filament-like structures which were ejected during the spreading phase of the drop impact. These filament-like ejections were classified as forming from both prompt- (Pan et al., 2010) and corona-type splashes (Ashida et al., 2020), which may be due to the loose definition for prompt and corona splash mechanisms within the literature (Josserand and Thoroddsen, 2016). We were unable to track the positions of these secondary drops or quantify them 
(a) Filament-like structures are ejected during spreading and instabilities form at the rim

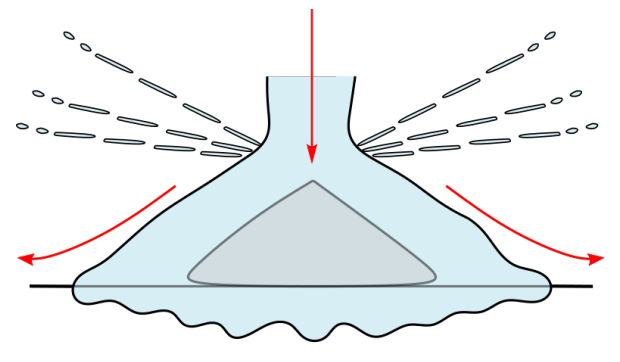

(b) Instabilities can pinch-off during retraction, followed by partial rebound of drop

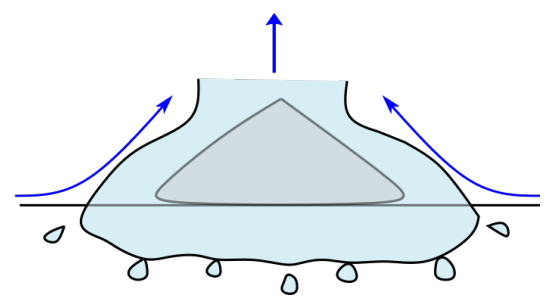

Figure 6. A schematic diagram of a supercooled water drop impact on an ice particle and subsequent secondary drop formation during (a) the spreading phase and (b) the retraction phase.

with our current high-speed camera or RPicams configurations. As the kinetic energy is transferred from that of a vertical to horizontal motion at impact, the water drop spread out radially, and instabilities at the rim were also observed. Figure 6(b) depicts the retraction of the drop, which caused the instabilities to 'pinch off' or rupture, followed by partial rebound. On superhydrophobic surfaces, rupturing of the instabilities has been attributed to surface tension (Zhang et al., 2020). Our glass slide, coated in a water-repellent, is probably superhydrophobic, and surface tension is likely the cause of the rupture of the rim instabilities.

As the ice particles were placed on a flat glass slide, during impact, the supercooled drop spread across the ice particle and on to the glass slide where the larger $>0.1 \mathrm{~mm}$ diameter sized secondary drops formed. We acknowledge that the glass slide presents an artificially flat surface compared to atmospheric conditions. However, a study by Schremb et al. (2018) showed that, on an elevated ice surface, the thin film of a supercooled water drop with a diameter of $\sim 4 \mathrm{~mm}$ and similar We and Re numbers at $-14{ }^{\circ} \mathrm{C}$ was ejected and subsequently ruptured, forming secondary drops. While quantification was not the focus of their study it was observed that the rim of the supercooled water drop was largely frozen, but only some of the secondary drops were observed as ice. The size of the secondary drops formed in the study by Schremb et al. (2018) is comparable to our secondary drops despite the different generation mechanism. Furthermore, water drops with diameters between $\sim 3-4 \mathrm{~mm}$ colliding with a steel disk of $\sim 4 \mathrm{~mm}$ in diameter Rozhkov et al. (2002) and water drops with diameters of 6 mm colliding with an iron cylinder of the same diameter Villermaux and Bossa (2011) produced numerous secondary drops, although again no quantification was made. Clearly, when a flat surface like the glass slide used in this study is not present, secondary drops are still formed, emitted from the rim of the thin film during impact. Whether this impacts on the number of secondary drops formed is difficult to ascertain without further studies.

We observed a decrease in secondary drop formation at $\mathrm{T}<-8{ }^{\circ} \mathrm{C}$. Quantification of our secondary drops was made during the retraction phase of the supercooled water drop impact, and the supercooled water drops spent a prolonged time in contact with the ice particle. For example, the first drops formed during retraction were observed at $\mathrm{t} \sim 133 \mathrm{~ms}$ in Fig. 3 at $-5{ }^{\circ} \mathrm{C}$, 

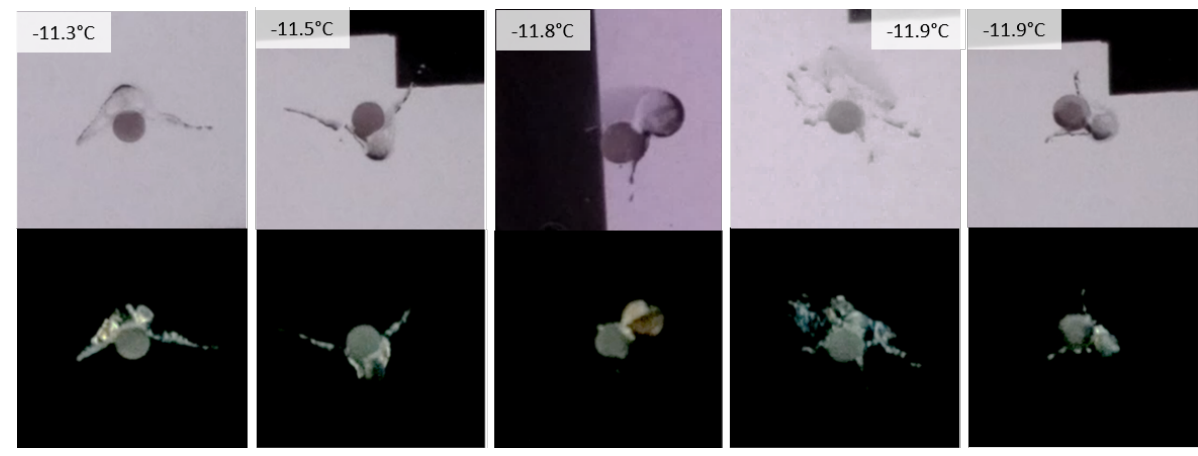

Figure 7. Frames from the RPicams configuration approximately $10 \mathrm{~s}$ after a supercooled water drop impact for experiments at $\mathrm{T} \leq-11^{\circ} \mathrm{C}$.

whereas, the first secondary drops were observed at $t \sim 5 \mathrm{~ms}$ for the supercooled water drop impact on an elevated ice target studied by Schremb et al. (2018) at $-14{ }^{\circ} \mathrm{C}$. If we consider our results at $\mathrm{T} \leq 11{ }^{\circ} \mathrm{C}$, the average number of secondary drops formed was 1.6 per collision, of which an average number of 0.4 secondary drops froze per collision. Moreover, Fig. 7 shows the frames after a supercooled water drop impact with an ice particle for the experiments at $\mathrm{T}<-11^{\circ} \mathrm{C}$. Here, it is clear to see how the lower temperature impacted on the retraction phase of the supercooled water drop, and hence, secondary drop formation. The growth velocity of ice in supercooled water increases with decreasing temperature. At $\mathrm{T}=-2{ }^{\circ} \mathrm{C}$ it is around $0.2 \mathrm{~cm} \mathrm{~s}^{-1}$, whereas at $\mathrm{T}=-10{ }^{\circ} \mathrm{C}$ it is around $5 \mathrm{~cm} \mathrm{~s}^{-1}$ (see Pruppacher and Klett, 1997, chapter 16). This, along with the transfer of heat away from the freezing drop, results in a finite amount of time that a given size of liquid water can remain in contact with ice without completely freezing onto the ice. We believe the decrease in secondary drop formation at $\mathrm{T}<-8{ }^{\circ} \mathrm{C}$ may be due to the artificially flat geometry presented by the glass slide and to the large size of the incident drop, both factors which prolonged the interaction time between the supercooled water drop and ice. For example, the supplementary videos from Schremb et al. (2018) showed several secondary drops forming even at $-14{ }^{\circ} \mathrm{C}$, more than we observed at our lowest temperatures of $-12{ }^{\circ} \mathrm{C}$.

The averaged freezing fraction of secondary drops $\bar{\Phi}$ in Fig. 5 shows that the freezing fraction at $\mathrm{T}>-12^{\circ} \mathrm{C}$ is fairly consistent with $\bar{\Phi} \sim 0.3$. We believe that the freezing fraction of the secondary drops is independent of the number of drops formed. For example, at $\mathrm{T} \leq-11^{\circ} \mathrm{C}$ the number of secondary drops formed reduces significantly, but the averaged freezing fraction of the secondary drops remains consistent with warmer temperature collisions. Also, Schremb et al. (2018) suggested that seeding ice crystals transported during the initial spreading phase when ice shear rates were highest could explain why freezing occurred predominately around the rim of the supercooled water drop. For our secondary drops formed at $\mathrm{T}>-12{ }^{\circ} \mathrm{C}$, we believe a similar mechanism occurred and that the majority of the frozen secondary drops nucleated from seeding ice crystals rather than dendritic growth from the ice particle. This may also translate to the smaller secondary drops observed with the high-speed camera configuration as the drops formed during the very early stages of spreading. 


\subsection{Atmospheric Implications}

Observations within mixed-phase clouds often show ice crystal number concentrations higher than the numbers of ice nucleating particles present in the atmosphere. For instance, ice particle number concentrations exceeding $100 \mathrm{~L}^{-1}$, in shallow convection with cloud-top temperature no lower than $-12{ }^{\circ} \mathrm{C}$, have been observed over the UK (Crawford et al., 2012). Furthermore, thin mixed-phase layer clouds have been observed to continually generate snow (Westbrook and Illingworth, 2013). Conventional thinking would suggest that the ice in mixed-phase layer clouds should fall out, leaving the layer 'depleted' of INPs; however, the observations clearly show that ice continues to form in these clouds over time.

The rime-splintering SIP mechanism has been successful in predicting the glaciation of mixed-phase clouds in many cases (e.g. Harris-Hobbs and Cooper, 1987; Blyth and Latham, 1993, 1997; Phillips et al., 2001, 2005; Crosier et al., 2011; Huang et al., 2017). However, there are also numerous cases where significant concentrations of ice observed in clouds cannot be explained by the rime-splintering SIP mechanism. Hobbs and Rangno (1985) compiled tables of aircraft observations from a wide range of cloud environments where enhancements in ice particle concentrations over the background INP concentrations occurred. They found that ice enhancement was independent of the cloud-top temperature, but was strongly dependent on the broadness of the supercooled drop spectrum near the cloud-top. Hobbs and Rangno presented aircraft observations in small polar-maritime cumuli that displayed ice enhancement. Their discussion highlighted that ice enhancement proceeded in two stages. The first stage consisted of the formation of frozen drops, $<400 \mu \mathrm{m}$ diameter, and small graupel particles, $<1 \mathrm{~mm}$ diameter. The second stage was characterised by the appearance of high concentrations of vapour-grown ice crystals in the upper regions of the cloud. A key finding of this series of papers was that high concentrations of small ice particles appeared simultaneously with frozen drizzle drops. Furthermore, Rangno and Hobbs (2001) showed that large supercooled drops were often a requirement for ice enhancement in moderately cooled Arctic stratiform clouds, and ice enhancement was often coincident with observations of large supercooled raindrops.

Supercooled drizzle drops and raindrops are common in convective clouds (e.g. Crawford et al., 2012; Taylor et al., 2016), as are large ice particles. Hence, because there is a broad continuum of drizzle and raindrop sizes, where the larger drops freeze first, followed by accretion of the smaller unfrozen drops that 'Mode 2', the collision of supercooled water drops with ice particles more massive, may be of importance in a wide range of clouds.

\section{Conclusions}

In this study, we confirmed that during collisions of supercooled water drops with ice particles, frozen secondary drops formed over the temperature range of $-4{ }^{\circ} \mathrm{C}$ to $-12{ }^{\circ} \mathrm{C}$. Our main findings are:

1. Approximately 5 to 10 secondary drops are formed during the receding break-up of the retraction phase of a supercooled water drop $(\mathrm{D}=5 \mathrm{~mm})$ after collision with an ice particle $(\mathrm{D}=6 \mathrm{~mm})$ placed on a glass slide.

2. An average of $30 \%$ of these secondary drops formed froze over the temperature range of $-4{ }^{\circ} \mathrm{C}$ to $-12{ }^{\circ} \mathrm{C}$. 
https://doi.org/10.5194/acp-2021-557

Preprint. Discussion started: 15 July 2021

(c) Author(s) 2021. CC BY 4.0 License.

(c) (i)

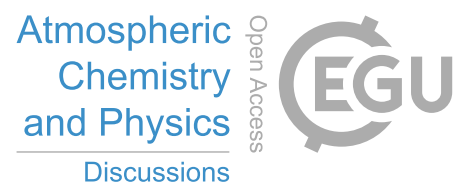

3. Experiments with a high-speed camera highlighted that secondary drops formed as a jet of smaller droplets produced separately from the receding break-up of the drop. No quantification of the freezing fraction of the secondary ice drops can currently be made.

Further work is needed to investigate the secondary drop formation without the influence of the glass slide, and this SIP mechanism over a larger range of supercooled drop sizes, temperatures, and interaction parameters. 
https://doi.org/10.5194/acp-2021-557

Preprint. Discussion started: 15 July 2021

(c) Author(s) 2021. CC BY 4.0 License.

\section{Appendix A}

Table A1. Total number of satellite drops and the number of frozen satellite drops for each experiment

\begin{tabular}{|c|c|c|c|}
\hline & Temperature $\left({ }^{\circ} \mathbf{C}\right)$ & Total number of secondary drops & Frozen secondary drops \\
\hline \multirow[t]{6}{*}{ Direct } & -4.2 & 14 & 1 \\
\hline & -4.2 & 0 & 0 \\
\hline & -5.3 & 7 & 6 \\
\hline & -5.5 & 10 & 2 \\
\hline & -7.8 & 12 & 2 \\
\hline & -9.9 & 7 & 0 \\
\hline \multirow[t]{26}{*}{ Partial } & -3.8 & 16 & 5 \\
\hline & -4.0 & 5 & 1 \\
\hline & -4.0 & 8 & 5 \\
\hline & -4.3 & 9 & 6 \\
\hline & -5.6 & 5 & 0 \\
\hline & -5.6 & 5 & 1 \\
\hline & -5.8 & 9 & 5 \\
\hline & -6.0 & 4 & 1 \\
\hline & -6.0 & 8 & 2 \\
\hline & -6.1 & 2 & 1 \\
\hline & -6.1 & 12 & 3 \\
\hline & -7.7 & 17 & 7 \\
\hline & -8.0 & 5 & 0 \\
\hline & -8.0 & 11 & 7 \\
\hline & -8.1 & 8 & 1 \\
\hline & -8.5 & 16 & 0 \\
\hline & -9.4 & 0 & 0 \\
\hline & -9.4 & 21 & 6 \\
\hline & -9.8 & 11 & 4 \\
\hline & -10.0 & 2 & 2 \\
\hline & -10.1 & 10 & 6 \\
\hline & -11.3 & 0 & 0 \\
\hline & -11.5 & 4 & 1 \\
\hline & -11.8 & 4 & 1 \\
\hline & -11.9 & 0 & 0 \\
\hline & -11.9 & 0 & 0 \\
\hline
\end{tabular}


https://doi.org/10.5194/acp-2021-557

Preprint. Discussion started: 15 July 2021

(c) Author(s) 2021. CC BY 4.0 License.

Table A2. The mean $(\bar{\Phi})$ and standard deviation $(\sigma)$ of the fraction of frozen secondary drops within a specified temperature interval (T interval) along with the number of experiments (n) within the T interval, the average degree of supercooling within the temperature interval $(\bar{T})$ and the error in the sample mean $\left(\sigma_{\bar{\Phi}}\right)$.

\begin{tabular}{ccccccc}
\hline T interval $\left({ }^{\circ} \mathrm{C}\right)$ & $\bar{T}\left({ }^{\circ} \mathrm{C}\right)$ & $\bar{\Phi}$ & $\sigma$ & $\mathrm{n}$ & $\sigma_{\bar{\Phi}}$ \\
\hline-3.8 & -4.3 & -4.1 & 0.4 & 0.3 & 5 & 0.1 \\
-5.3 & -5.8 & -5.6 & 0.4 & 0.3 & 5 & 0.2 \\
-6.0 & -6.1 & -6.1 & 0.3 & 0.1 & 4 & 0.1 \\
-7.7 & -7.8 & -7.8 & 0.3 & 0.2 & 2 & 0.1 \\
-8.0 & -8.5 & -8.2 & 0.2 & 0.3 & 4 & 0.2 \\
-9.4 & -9.9 & -9.7 & 0.2 & 0.2 & 3 & 0.1 \\
-10.0 & -10.1 & -10.1 & 0.8 & 0.3 & 2 & 0.2 \\
-11.3 & -11.9 & -11.7 & 0.3 & 0 & 2 & 0 \\
\hline
\end{tabular}

Table A3. The mean $\left(\bar{N}_{s}\right)$ and standard deviation $(\sigma)$ of the number of secondary drops within a specified temperature interval (T interval) along with the number of experiments (n) within the T interval, the average degree of supercooling within the temperature interval $(\bar{T})$ and the error in the sample mean $\left(\sigma_{\bar{N}_{s}}\right)$.

\begin{tabular}{lllllll}
\hline \multicolumn{2}{c}{ T interval $\left({ }^{\circ} \mathrm{C}\right)$} & $\bar{T}\left({ }^{\circ} \mathrm{C}\right)$ & $\bar{N}_{s}$ & $\sigma$ & $\mathrm{n}$ & $\sigma_{\bar{N}_{s}}$ \\
\hline-3.8 & -4.3 & -4.1 & 8.7 & 5.9 & 6 & 2.4 \\
-5.3 & -5.8 & -5.6 & 7.2 & 2.3 & 5 & 1.0 \\
-6.0 & -6.1 & -6.1 & 6.5 & 4.4 & 4 & 2.2 \\
-7.7 & -7.8 & -7.8 & 14.5 & 3.5 & 2 & 2.5 \\
-8.0 & -8.5 & -8.2 & 10.0 & 4.7 & 4 & 2.3 \\
-9.4 & -9.9 & -9.6 & 9.8 & 8.8 & 4 & 4.4 \\
-10.0 & -10.1 & -10.1 & 6.0 & 5.7 & 2 & 4.0 \\
-11.3 & -11.9 & -11.7 & 1.6 & 2.2 & 5 & 1.0 \\
\hline
\end{tabular}

Acknowledgements. We acknowledge the US Department of Energy for funding the main part of this study. We also acknowledge funding from NERC (NE/T001496/1).

Data availability. All datasets are provided in Appendix A. 
https://doi.org/10.5194/acp-2021-557

Preprint. Discussion started: 15 July 2021

(c) Author(s) 2021. CC BY 4.0 License.

(c) (i)

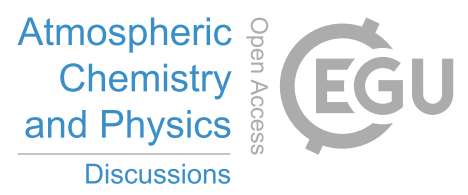

Video supplement. All video recordings from the high-speed configuration and RPicams configuration are deposited in Figshare, a FAIRaligned data repository and can be accessed at https://doi.org/10.48420/c.5476557.

Author contributions. VTJP and PJC conceived the original study. RLJ and PJC designed the new experimental setup with advice from 240 VTJP. RLJ and PJC performed the experiments. RLJ analysed the data and wrote the paper. VTJP and PJC provided comments on the paper.

Competing interests. The authors declare that they have no conflict of interest 


\section{References}

Antonini, C., Amirfazli, A., and Marengo, M.: Drop impact and wettability: From hydrophilic to superhydrophobic surfaces, Phys. Fluids, 24, 102 104, https://doi.org/10.1063/1.4757122, 2012.

Ashida, T., Watanabe, M., Kobayashi, K., Fujii, H., and Sanada, T.: Hidden prompt splashing by corona splashing at drop impact on a smooth dry surface, Phys. Rev. Fluids, 5, 011 601, https://doi.org/10.1103/PhysRevFluids.5.011601, 2020.

Blyth, A. M. and Latham, J.: Development of ice and precipitation in new mexican summertime cumulus, Q. J. R. Meteorol. Soc., 119, 91-120, https://doi.org/10.1002/qj.49711950905, 1993.

Blyth, A. M. and Latham, J.: A multi-thermal model of cumulus glaciation via the Hallett-Mossop process, Q. J. R. Meteorol. Soc., 123, 1185-1198, https://doi.org/10.1002/qj.49712354104, 1997.

Changnon, S. A.: Characteristics of Ice Storms in the United States, J. Appl. Meteorol., 42, 630-639, https://doi.org/10.1175/15200450(2003)042<0630:COISIT>2.0.CO;2, 2003.

Crawford, I., Bower, K. N., Choularton, T. W., Dearden, C., Crosier, J., Westbrook, C., Capes, G., Coe, H., Connolly, P. J., Dorsey, J. R., Gallagher, M. W., Williams, P., Trembath, J., Cui, Z., and Blyth, A.: Ice formation and development in aged, wintertime cumulus over the UK: observations and modelling, Atmos. Chem. and Phys., 12, 4963-4985, https://doi.org/10.5194/acp-12-4963-2012, 2012.

Crosier, J., Bower, K. N., Choularton, T. W., Westbrook, C. D., Connolly, P. J., Cui, Z. Q., Crawford, I. P., Capes, G. L., Coe, H., Dorsey, J. R., Williams, P. I., Illingworth, A. J., Gallagher, M. W., and Blyth, A. M.: Observations of ice multiplication in a weakly convective cell embedded in supercooled mid-level stratus, Atmos. Chem. Phys., 11, 257-273, https://doi.org/10.5194/acp-11-257-2011, 2011.

Dehaoui, A., Issenmann, B., and Caupin, F.: Viscosity of deeply supercooled water and its coupling to molecular diffusion, Proc. Natl. Acad. Sci. U.S.A., 112, 12 020-12 025, https://doi.org/10.1073/pnas.1508996112, 2015.

Elsom, D.: Deaths and injuries caused by lightning in the United Kingdom: analyses of two databases, Atmos. Res., 56, 325-334, https://doi.org/https://doi.org/10.1016/S0169-8095(00)00083-1, 2001.

Field, P. R. and Heymsfield, A. J.: Importance of snow to global precipitation, Geophys. Res. Lett., 42, 9512-9520, https://doi.org/https://doi.org/10.1002/2015GL065497, 2015.

Field, P. R., Lawson, R. P., Brown, P. R. A., Lloyd, G., Westbrook, C., Moisseev, D., Miltenberger, A., Nenes, A., Blyth, A., Choularton, T., Connolly, P., Buehl, J., Crosier, J., Cui, Z., Dearden, C., DeMott, P., Flossmann, A., Heymsfield, A., Huang, Y., Kalesse, H., Kanji, Z. A., Korolev, A., Kirchgaessner, A., Lasher-Trapp, S., Leisner, T., McFarquhar, G., Phillips, V., Stith, J., and Sullivan, S.: Secondary Ice Production: Current State of the Science and Recommendations for the Future, Meteorol. Monogr., 58, 7.1-7.20, https://doi.org/10.1175/AMSMONOGRAPHS-D-16-0014.1, 2017.

Hallett, J. and Mossop, S. C.: Production of secondary ice particles during the riming process, Nature, 249, 26-28, https://doi.org/10.1038/249026a0, 1974.

Harris-Hobbs, R. L. and Cooper, W. A.: Field Evidence Supporting Quantitative Predictions of Secondary Ice Production Rates, J. Atmos. Sci., 44, 1071-1082, https://doi.org/10.1175/1520-0469(1987)044<1071:FESQPO>2.0.CO;2, 1987.

Hobbs, P. V. and Rangno, A. L.: Rapid development of high ice particle concentrations in small polar maritime cumuliform clouds, J. Atmos. Sci., pp. 2710-2722, https://doi.org/10.1175/1520-0469(1990)047<2710:RDOHIP>2.0.CO;2.

Hobbs, P. V. and Rangno, A. L.: Ice particle concentrations in clouds, J. Atmos. Sci., 42, 2523-2549, https://doi.org/10.1175/15200469(1985)042<2523:IPCIC >2.0.CO;2, 1985 . 
Hrubý, J., Vinš, V., Mareš, R., Hykl, J., and Kalová, J.: Surface Tension of Supercooled Water: No Inflection Point down to -25 ${ }^{\circ}$ C, J. Phys. Chem. Lett., 5, 425-428, https://doi.org/10.1021/jz402571a, 2014.

Huang, Y., Blyth, A. M., Brown, P. R. A., Choularton, T. W., and Cui, Z.: Factors controlling secondary ice production in cumulus clouds,

Q. J. R. Meteorol. Soc., 143, 1021-1031, https://doi.org/10.1002/qj.2987, 2017.

Josserand, C. and Thoroddsen, S.: Drop Impact on a Solid Surface, Annu. Rev. Fluid Mech., 48, 365-391, https://doi.org/10.1146/annurevfluid-122414-034401, 2016.

Kanji, Z. A., Ladino, L. A., Wex, H., Boose, Y., Burkert-Kohn, M., Cziczo, D. J., and Krämer, M.: Overview of Ice Nucleating Particles,

Korolev, A. and Leisner, T.: Review of experimental studies of secondary ice production, Atmos. Chem. Phys., 20, 11767-11797, https://doi.org/10.5194/acp-20-11767-2020, 2020.

Ladino, L. A., Korolev, A., Heckman, I., Wolde, M., Fridlind, A. M., and Ackerman, A. S.: On the role of ice-nucleating aerosol in the formation of ice particles in tropical mesoscale convective systems, Geophys. Res. Lett., 44, 1574-1582, https://doi.org/https://doi.org/10.1002/2016GL072455, 2017.

Lasher-Trapp, S., Leon, D. C., DeMott, P. J., Villanueva-Birriel, C. M., Johnson, A. V., Moser, D. H., Tully, C. S., and Wu, W.: A Multisensor Investigation of Rime Splintering in Tropical Maritime Cumuli, J. Atmos. Sci., 73, 2547-2564, https://doi.org/10.1175/JAS-D-15-0285.1, 2016.

Latham, J. and Warwicker, R.: Charge transfer accompanying the splashing of supercooled raindrops on hailstones., Quart. J. Roy. Meteorol. Soc., 106, 559-568, https://doi.org/10.1002/qj.49710644912, 1980.

Lawson, R. P., Woods, S., and Morrison, H.: The Microphysics of Ice and Precipitation Development in Tropical Cumulus Clouds, J. Atmos. Sci., 72, 2429-2445, https://doi.org/10.1175/JAS-D-14-0274.1, 2015.

Levin, Z., Hobbs, P. V., and Taylor, G. I.: Splashing of water drops on solid and wetted surfaces: hydrodynamics and charge separation, Philos. Trans. R. Soc. A, 269, 555-585, https://doi.org/10.1098/rsta.1971.0052, 1971.

Lloyd, G., Choularton, T. W., Bower, K. N., Gallagher, M. W., Connolly, P. J., Flynn, M., Farrington, R., Crosier, J., Schlenczek, O., Fugal, J., and Henneberger, J.: The origins of ice crystals measured in mixed-phase clouds at the high-alpine site Jungfraujoch, Atmos. Chem. and Phys., 15, 12 953-12 969, https://doi.org/10.5194/acp-15-12953-2015, 2015.

Mossop, S. C.: Some Factors Governing Ice Particle Multiplication in Cumulus Clouds, J. Atmos. Sci., 35, 2033-2037, https://doi.org/10.1175/1520-0469(1978)035<2033:SFGIPM>2.0.CO;2, 1978.

Mossop, S. C. and Hallett, J.: Ice Crystal Concentration in Cumulus Clouds: Influence of the Drop Spectrum, Science, 186, 632-634, https://doi.org/10.1126/science.186.4164.632, 1974.

Pan, K. L., Tseng, K. C., and Wang, C. H.: Breakup of a droplet at high velocity impacting a solid surface, Exp. Fluids, 48, 143-156, https://doi.org/10.1007/s00348-009-0697-3, 2010.

Phillips, V. T., Patade, S., Gutierrez, J., and Bansemer, A.: Secondary Ice Production by Fragmentation of Freezing Drops: Formulation and Theory, J. Atmos. Sci., 76, 3031-3070, https://doi.org/10.1175/JAS-D-17-0190.1, 2018.

Phillips, V. T. J., Blyth, A. M., Brown, P. R. A., Choularton, T. W., and Latham, J.: The glaciation of a cumulus cloud over New Mexico, Q. J. R. Meteorol. Soc., 127, 1513-1534, https://doi.org/https://doi.org/10.1002/qj.49712757503, 2001.

Phillips, V. T. J., Andronache, C., Sherwood, S. C., Bansemer, A., Conant, W. C., Demott, P. J., Flagan, R. C., Heymsfield, A., Jonsson, H., Poellot, M., Rissman, T. A., Seinfeld, J. H., Vanreken, T., Varutbangkul, V., and Wilson, J. C.: Anvil glaciation in a deep cumulus 

Soc., 131, 2019-2046, https://doi.org/https://doi.org/10.1256/qj.04.85, 2005.

Pruppacher, H. R. and Klett, J. D.: Microphysics of clouds and precipitation, "Kluwer Academic Press", "Norwell”, 1997.

Púčik, T., Castellano, C., Groenemeijer, P., Kühne, T., Rädler, A. T., Antonescu, B., and Faust, E.: Large Hail Incidence and Its Economic and Societal Impacts across Europe, Mon. Weather Rev., 147, 3901-3916, https://doi.org/10.1175/MWR-D-19-0204.1, 2019.

Rangno, A. L. and Hobbs, P. V.: Ice particles in stratiform clouds in the Arctic and possible mechanisms for the production of high ice concentrations, J. Geophys. Res., 106, 15 065-15 075, https://doi.org/10.1029/2000JD900286, 2001.

Roisman, I. V.: Inertia dominated drop collisions. II. An analytical solution of the Navier-Stokes equations for a spreading viscous film, Phys. Fluids, 21, 052 104, https://doi.org/10.1063/1.3129283, 2009.

Rozhkov, A., Prunet-Foch, B., and Vignes-Adler, M.: Impact of water drops on small targets, Phys. Fluids, 14, 3485-3501, https://doi.org/10.1063/1.1502663, 2002.

Schremb, M., Roisman, I. V., and Tropea, C.: Normal impact of supercooled water drops onto a smooth ice surface: experiments and modelling, J. Fluid Mech., 835, 1087—1107, https://doi.org/10.1017/jfm.2017.797, 2018.

Taylor, J. W., Choularton, T. W., Blyth, A. M., Liu, Z., Bower, K. N., Crosier, J., Gallagher, M. W., Williams, P. I., Dorsey, J. R., Flynn, M. J., Bennett, L. J., Huang, Y., French, J., Korolev, A., and Brown, P. R. A.: Observations of cloud microphysics and ice formation during COPE, Atmos. Chem. Phys., 16, 799-826, https://doi.org/10.5194/acp-16-799-2016, 2016.

Testik, F. Y., Barros, A. P., and Bliven, L. F.: Toward a Physical Characterization of Raindrop Collision Outcome Regimes, J. Atmos. Sci., 68, 1097-1113, https://doi.org/10.1175/2010JAS3706.1, 2011.

Villermaux, E. and Bossa, B.: Drop fragmentation on impact, J. Fluid Mech., 668, 412—-435, https://doi.org/10.1017/S002211201000474X, 2011.

335 Westbrook, C. D. and Illingworth, A. J.: The formation of ice in a long-lived supercooled layer cloud, Q. J. R. Meteorol. Soc., 139, 22092221, https://doi.org/10.1002/qj.2096, 2013.

Zhang, H., Zhang, X., Yi, X., He, F., Niu, F., and Hao, P.: Asymmetric splash and breakup of drops impacting on cylindrical superhydrophobic surfaces, Phys. Fluids, 32, 122 108, https://doi.org/10.1063/5.0032910, 2020. 